Article

\title{
Encapsulation of Risperidone by Methylated $\beta$-Cyclodextrins: Physicochemical and Molecular Modeling Studies
}

\author{
Laura Sbârcea $^{1,2}$, Ionuț-Mihai Tănase ${ }^{3}$, Adriana Ledeți ${ }^{1,2} * \mathbb{D}$, Denisa Cîrcioban ${ }^{1,2}$ (D), \\ Gabriela Vlase ${ }^{4}$, Paul Barvinschi ${ }^{5}$, Marinela Miclău ${ }^{6}$, Renata-Maria Văruţ ${ }^{7}$, \\ Cristina Trandafirescu ${ }^{8}$ and Ionuț Ledeți ${ }^{1,2,3}{ }^{\mathbb{D}}$
}

1 Department of Pharmacy I, Faculty of Pharmacy, "Victor Babeş" University of Medicine and Pharmacy, 2 Eftimie Murgu Square, 300041 Timisoara, Romania; sbarcea.laura@umft.ro (L.S.); circioban.denisa@umft.ro (D.C.); ionut.ledeti@umft.ro (I.L.)

2 Advanced Instrumental Screening Center, Faculty of Pharmacy, "Victor Babes" University of Medicine and Pharmacy, 2 Eftimie Murgu Square, 300041 Timisoara, Romania

3 Faculty of Industrial Chemistry and Environmental Engineering, Politehnica University of Timisoara, 6 Vasile Parvan Blvd, 300223 Timisoara, Romania; ionut.tanase@student.upt.ro

4 Research Centre for Thermal Analysis in Environmental Problems, West University of Timisoara, 16 Pestalozzi Street, 300115 Timisoara, Romania; gabriela.vlase@e-uvt.ro

5 Faculty of Physics, West University of Timisoara, 4 Vasile Parvan Blvd, 300223 Timisoara, Romania; pc_barvi@yahoo.fr

6 National Institute for Research and Development in Electrochemistry and Condensed Matter, 144 Dr. A. Păunescu-Podeanu Street, 300587 Timisoara, Romania; marinela.miclau@gmail.com

7 Faculty of Pharmacy, University of Medicine and Pharmacy Craiova, 2-4 Petru Rares Street, 200349 Craiova, Romania; rennata_maria@yahoo.com

8 Department of Pharmacy II, Faculty of Pharmacy, “Victor Babeş” University of Medicine and Pharmacy, 2 Eftimie Murgu Square, 300041 Timisoara, Romania; trandafirescu.cristina@umft.ro

* Correspondence: afulias@umft.ro

Academic Editors: Tivadar Feczkó and László Biczók

Received: 9 November 2020; Accepted: 1 December 2020; Published: 3 December 2020

\begin{abstract}
Risperidone (RSP) is an atypical antipsychotic drug which acts as a potent antagonist of serotonin-2 (5TH2) and dopamine-2 (D2) receptors in the brain; it is used to treat schizophrenia, behavioral and psychological symptoms of dementia and irritability associated with autism. It is a poorly water soluble benzoxazole derivative with high lipophilicity. Supramolecular adducts between drug substance and two methylated $\beta$-cyclodextrins, namely heptakis(2,6-di-O-methyl)- $\beta$ cyclodextrin (DM- $\beta-C D)$ and heptakis $(2,3,6$-tri-O-methyl)- $\beta$-cyclodextrin (TM- $\beta-C D)$ were obtained in order to enhance RSP solubility and improve its biopharmaceutical profile. The inclusion complexes were evaluated by means of thermoanalytical methods (TG—-thermogravimetry/DTG—derivative thermogravimetry/HF- heat flow), powder X-ray diffractometry (PXRD), universal-attenuated total reflectance Fourier transform infrared (UATR-FTIR), UV spectroscopy and saturation solubility studies. Job's method was employed for the determination of the stoichiometry of the inclusion complexes, which was found to be 2:1 for both guest-host systems. Molecular modeling studies were carried out for an in-depth characterization of the interaction between drug substance and cyclodextrins (CDs). The physicochemical properties of the supramolecular systems differ from those of RSP, demonstrating the inclusion complex formation between drug and CDs. The RSP solubility was enhanced as a result of drug encapsulation in the CDs cavity, the higher increase being obtained with DM- $\beta$-CD as host; the guest-host system RSP/DM- $\beta$-CD can thus be a starting point for further research in developing new formulations containing RSP, with enhanced bioavailability.
\end{abstract}


Keywords: risperidone; cyclodextrins; molecular encapsulation; inclusion complex; solubility

\section{Introduction}

Cyclodextrins (CDs) are macrocyclic molecules that have been extensively used in the last decade in the pharmaceutical field, cosmetics, food, textile, separation science and chemical industries. They contain six, seven or eight D-glucopyranose units ( $\alpha, \beta$ and $\gamma$-cyclodextrin) linked in $\alpha(1-4)$ to form a hollow, truncated-cone-shape structure with hydrophilic outer surface and hydrophobic internal cavity. This particular structure is responsible for CDs property of establishing specific interaction with a variety of drug molecules; guest-host inclusion complexes are thus formed by trapping the drug into CD cavity [1-5]. Molecular encapsulation of bioactive compounds in the CDs has achieved pharmaceutical relevance since the physical, chemical and biopharmaceutical characteristics of guest molecules are remarkably improved. CD inclusion complexes can increase the solubility of insoluble drug molecules and the antioxidant properties, can improve the chemical stability, the biological activity and the bioavailability of guest substances, may reduce/eliminate the unpleasant smell and taste, may prevent drug-excipient or drug-drug interactions [6-15]. $\beta$-cyclodextrin $(\beta-C D)$ is the most frequently used in the pharmaceutical field due to its availability, appropriate internal cavity size for an important number of drug substances and economic advantages. $\beta$-CD is also non-toxic, biodegradable, but it has a limited aqueous solubility $[2,4,16]$. In order to enhance its solubility, CD derivatives have been developed, among them methylated $\beta$-CDs $[17,18]$.

Risperidone (abbreviated RSP in this paper), 3-[2-[4-(6-fluoro-1,2-benzoxazol-3-yl)piperidin-1-yl]ethyl]2-methyl-6,7,8,9-tetrahydropyrido [1,2-a]pyrimidin-4-one (Figure 1) is an atypical antipsychotic drug, belonging to the class of pyridopyrimidines used in treating schizophrenia, behavioral and psychological symptoms of dementia and irritability associated with autism $[19,20]$. It is a potent inhibitor of serotonin-2 (5TH2) and dopamine-2 (D2) receptors in the brain. RSP belongs to class II in the Biopharmaceutics Classification System (BCS); it is practically insoluble in water and exhibits high lipophilicity ( $\log P$ of 3.49) $[19,21,22]$. RSP presents the ability to form polymorphs [19], that can possess different solubility, dissolution rates, affecting thus the biopharmaceutical profile of drug substance [23].

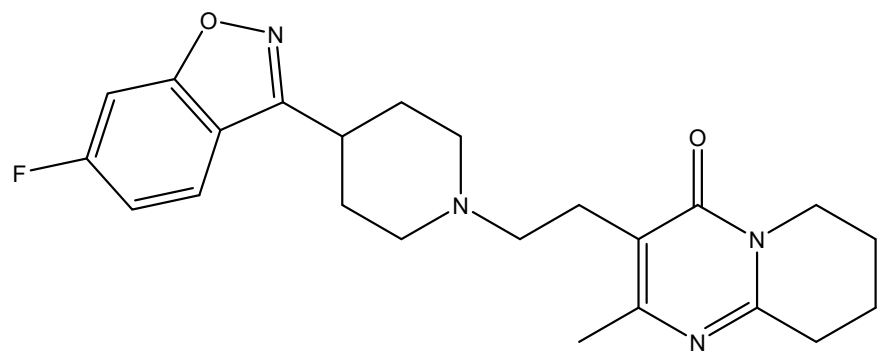

Figure 1. Structural formula of risperidone (RSP).

Among the different strategies aiming at improving the solubility of drug substances with low solubility and high permeability, inclusion complexation with CDs is a valuable approach [23]. Encapsulation of RSP in CDs has been mentioned in the several papers; inclusion complexes of drug with $\beta-C D$ and hydroxypropyl- $\beta-C D(H P-\beta-C D)$ have been investigated and formulated for parenteral administration and nasal application [24,25], solid dispersion of risperidone with methyl- $\beta$-cyclodextrin has been studied and incorporated into orally disintegrating tablets for faster release of drug substance [22]. Moreover, the solubility of RSP in aqueous solutions of $\alpha-, \beta-, \gamma$ - and HP- $\beta$-CDs has been assessed [26].

The major challenge with the design of oral dosage forms lies with their poor bioavailability. Solubility is an essential property of drugs, being one of the most critical and important parameters 
influencing their bioavailability. Thus, the enhancement of drug solubility and thereby its bioavailability remains one of the most challenging aspects of the drug development, process especially for oral pharmaceutical formulation [27].

In this study we aimed to improve RSP solubility by obtaining the inclusion complexes of drug substance with two methylated cyclodextrins, heptakis(2,6-di-O-methyl)- $\beta$-cyclodextrin (DM- $\beta$-CD) and heptakis(2,3,6-tri-O-methyl)- $\beta$-cyclodextrin (TM- $\beta$-CD). UV-spectroscopy, powder X-ray diffractometry (PXRD), thermogravimetry (TG), derivative thermogravimetry (DTG), heat flow (HF) and FTIR spectroscopy were used to evaluate the RSP/CD systems. In addition, molecular modeling studies were carried out for the geometry of complexes investigation. The saturation solubility studies were further performed in order to assess the increase in RSP solubility.

\section{Results and Discussion}

\subsection{Stoichiometry Determination of RSP/CD Inclusion Complexes}

Job's method was used to estimate the stoichiometry of the inclusion complexes [28]. According to this method the inclusion complex stoichiometry can be determined when a measurable physical parameter that correlates linearly with the complex concentration (i.e., absorbance) is plotted against guest mole fraction. The stoichiometry is provided by the value of the molar ratio $\mathrm{R}$ that correlates with the maximum concentration of the complex $[10,12,29]$. The maximum variation $(\Delta A)$ in RSP absorption is noticed at mole fraction of $\sim 0.66$ in the presence of both DM- $\beta-C D$ and TM- $\beta-C D$, which suggests that the main guest-host stoichiometry is 2:1 for both inclusion complexes (Figure 2).

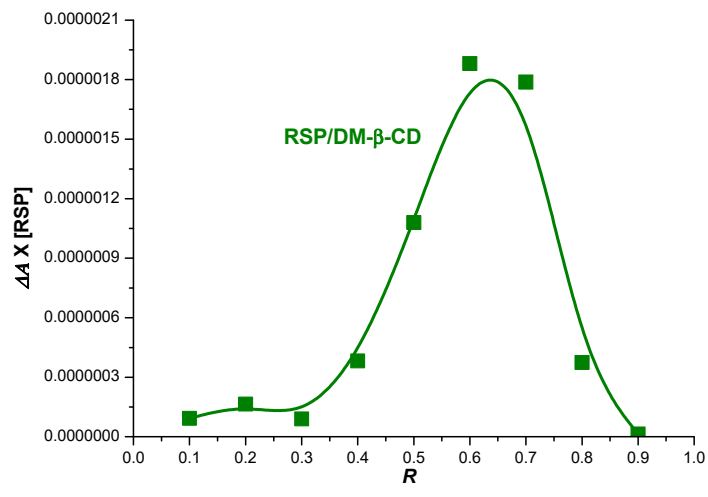

(a)

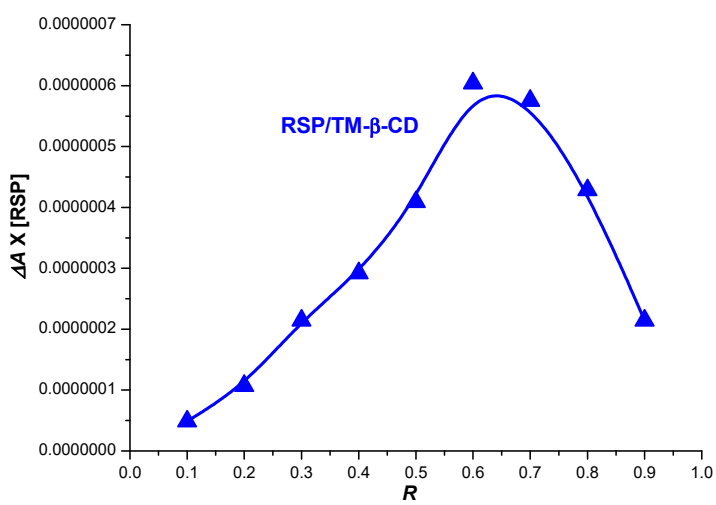

(b)

Figure 2. Job's plot corresponding to RSP/heptakis(2,6-di-O-methyl)- $\beta$-cyclodextrin (DM- $\beta$-CD) (a) and RSP/heptakis(2,3,6-tri-O-methyl)- $\beta$-cyclodextrin (TM- $\beta$-CD) (b) inclusion systems.

\subsection{Molecular Modeling Studies}

Molecular modeling was used in order to predict the spatial conformation of RSP/CD inclusion complexes in 2:1 ratio and to elucidate the type of bonds involved in the interaction between drug substance and the two CDs. As the expected stoichiometry of RSP:CD inclusion complexes was 2:1, two consecutive docking cycles were carried out starting and selecting the best result from each cycle.

The molecular docking analysis was performed using the Autodock 4.2.6 software together with the AutoDockTools [30]. The software applies a semi-empirical free energy force field and grid-based docking to assess conformations during docking process. The force field includes six pair-wise evaluations $(V)$ and an estimate of the conformational entropy lost upon binding ( $\Delta$ Sconf):

$$
\Delta G=\left(V_{\text {bound }}^{L-L}-V_{\text {unbound }}^{L-L}\right)+\left(V_{\text {bound }}^{T-T}-V_{\text {unbound }}^{T-T}\right)+\left(V_{\text {bound }}^{T-L}-V_{\text {unbound }}^{T-L}+\Delta S_{\text {conf }}\right)
$$

where $L$ refers to the "ligand" and $T$ refers to the "target" in a ligand-target docking calculation. Each of the pair-wise energetic terms includes evaluations for dispersion/repulsion, hydrogen 
bonding, electrostatics and desolvation [31]. Following the redocking analysis, we calculated the root-mean-square deviation (RMSD) values to be lower than $0.4 \mathrm{~A}$, suggesting the robustness and repeatability of the docking analysis.

The binding free energy values calculated was $-12.48 \mathrm{kcal} / \mathrm{mol}$ for the RSP/DM- $\beta$-CD (2:1) inclusion complex and $-13.13 \mathrm{kcal} / \mathrm{mol}$ for RSP/TM- $\beta-\mathrm{CD}(2: 1)$ inclusion system. According to our data, the RSP/TM- $\beta-C D(2: 1)$ is more stable than the RSP/DM- $\beta-C D(2: 1)$ because it has a lower value of binding free energy. Figures 3 and 4 present the theoretical RSP/CD inclusion complexes, as rendered in the PyMOL [32] and Discovery Studio molecular visualization systems, simulated in 2:1 molar ratio.

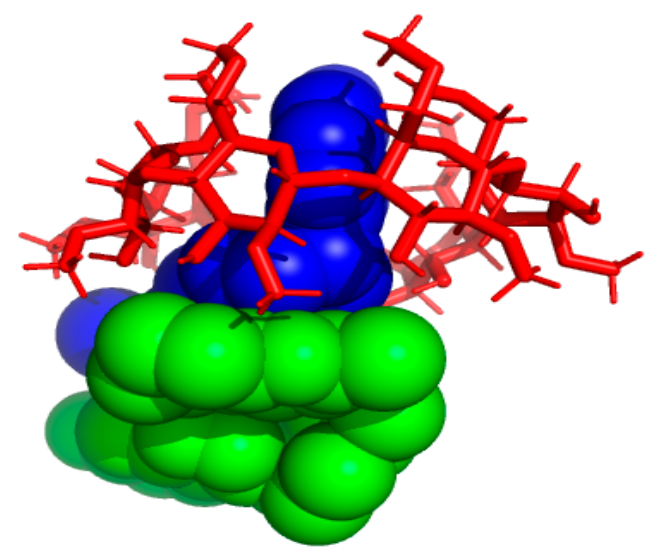

(a)

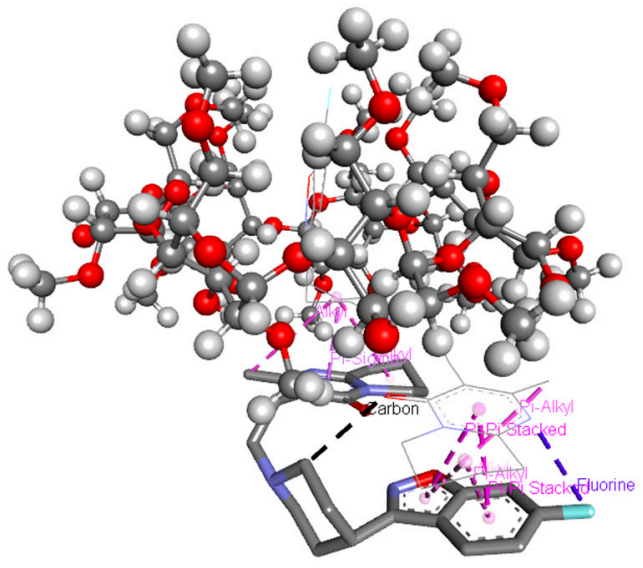

(c)

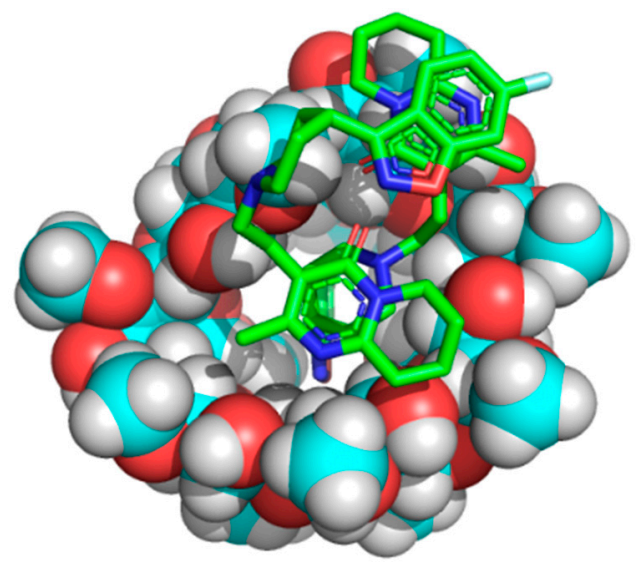

(b)

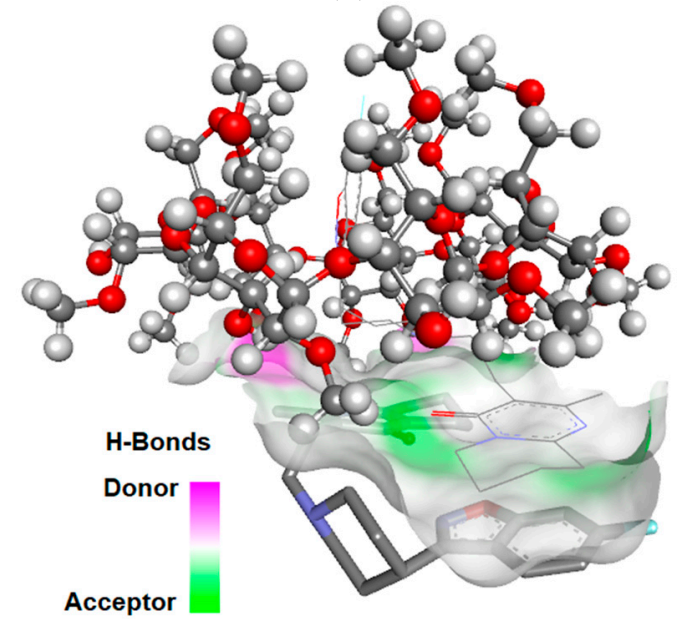

(d)

Figure 3. Inclusion complex simulation for a 2:1 molar ratio between RSP and DM- $\beta$-CD. Images (a), (b) show the inclusion complex from the secondary face of DM- $\beta$-CD's cavity. RSP guest molecules are represented in spheres green and blue (a), in sticks colored by element (b) while DM- $\beta-C D$ is represented in red sticks (a), in sphere colored by element (b); image (c) shows contacts between RSP and DM- $\beta-C D, R S P$ is colored by element, DM- $\beta-C D$ is presented in ball and sticks; image (d) show $\mathrm{H}$-bond surface interaction between RSP and DM- $\beta-C D$.

In the 3D images of the RSP/DM- $\beta$-CD (2:1) interaction we noticed the presence of two Pi-donor non-classical hydrogen bonds, one between fluorine (RSP included in DM- $\beta-C D$ ) and the hydrogen (hydrogen methoxy group) of a glucopyranose unit with a length of $2.37 \AA$, and second between 1,2-oxazolic heterocyclic oxygen and the hydrogen methoxy group of DM- $\beta$-CD (3.04 $\AA$ ). The benzene ring near the 1,2-oxazolic heterocycle forms Pi-sigma interaction with a length of $2.68 \AA$ with hydrogen methoxy group of carbohydrate moiety (position 6). The fourth non-classical hydrogen bond occurs between the nitrogen group from the 1,2-oxazolic heterocycle and the hydrogen from position 4 of a carbohydrate moiety. The second RSP molecule interacts strongly with the one included in the 
DM- $\beta$-CD cavity, with five Pi-alkyl interactions ( $4.14 \AA$, $4.76 \AA$, $5.40 \AA, 4.60 \AA$ and $4.80 \AA$, respectively) two Pi-Pi stacked interactions ( $3.68 \AA$ and $4.77 \AA$ ) and one halogen bond (Pi-fluorine interaction) with a length of $3.27 \AA$.

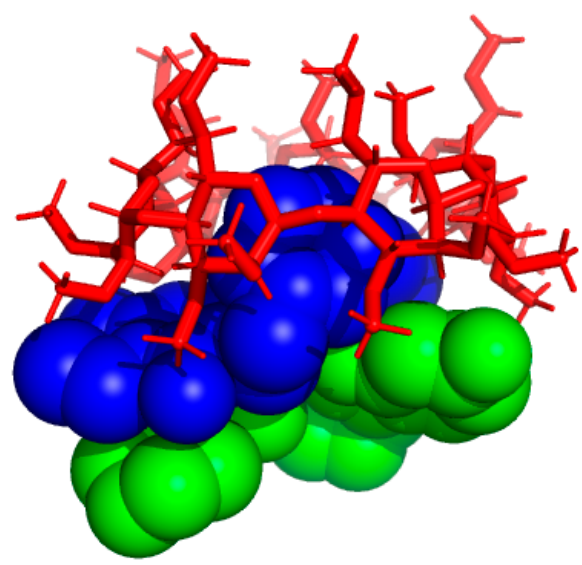

(a)

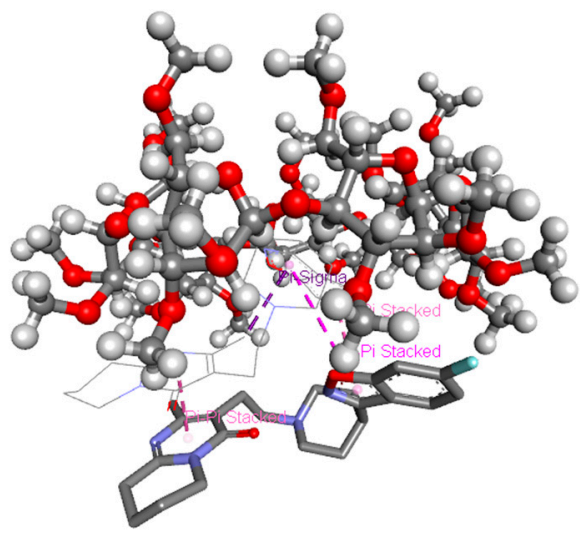

(c)

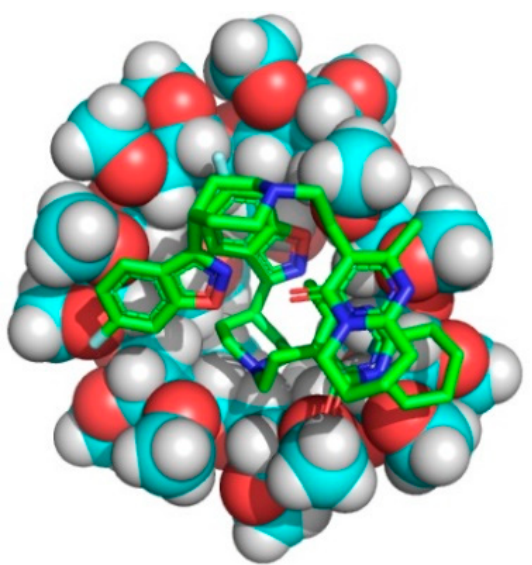

(b)

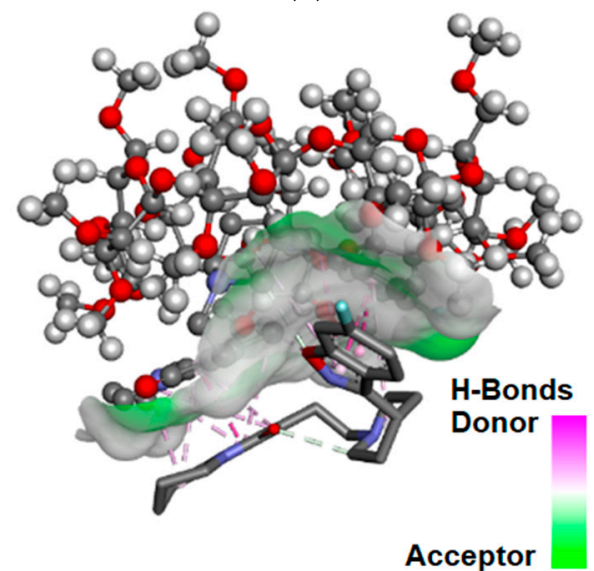

(d)

Figure 4. Molecular docking results revealing the geometry of inclusion complex for 2:1 molar ratio between RSP and TM- $\beta-C D$. Guest substance is presented in spheres green and blue (a), in sticks colored by element (b) and host TM- $\beta-C D$, in red sticks (a), in sphere colored by element (b); image (c) shows contacts between RSP colored by element and TM- $\beta-C D$, in ball and sticks; image (d) shows H-bond surface interaction between RSP and TM- $\beta-C D$.

Analyzing the 3D images of the RSP/TM- $\beta-C D(2: 1)$ interaction, we observe that three non-classical hydrogen bonds are formed between the 1,2-oxazole heterocyclic oxygen of RSP included in cavity and the hydrogen (position 4) of three glucopyranose units with a length of $3.65 \AA, 3.77 \AA$ and $3.72 \AA$. Two intramolecular Pi-sigma bonds of $3.35 \AA$ and $3.59 \AA$, respectively, are established between the 1,2-oxazole heterocycle/benzene ring and the pyrimidin-4-one methyl radical, that leads to conformation changes in the ligand structured included in the cavity. The second RSP molecule not included in the cavity binds to TM- $\beta-C D$ through a non-classical Pi-donor hydrogen bond between fluorine and the hydrogen of a hydroxyl group (position 2), having a length of $3.52 \AA$. Moreover, the second molecule of RSP binds to the one included in the cavity by three Pi-Pi stacked interactions with lengths of $3.46 \AA$, $4.76 \AA$ and $5.76 \AA$, respectively. A non-classical hydrogen bond with a length of $2.76 \AA$ also appears between the two RSP molecules, involving the oxygen of the 1,2-oxazolic heterocyclic moiety and the carbon atom from position 2 of the piperidine ring. 


\subsection{X-ray Diffraction Studies}

PXRD was employed in order to characterize the interaction between RSP and CDs in solid state. Figure 5 presents the diffraction patterns of RSP, DM- $\beta-C D, T M-\beta-C D$ and RSP/CD binary systems obtained by physical mixture (PM) and by kneading (kneaded products, KP).

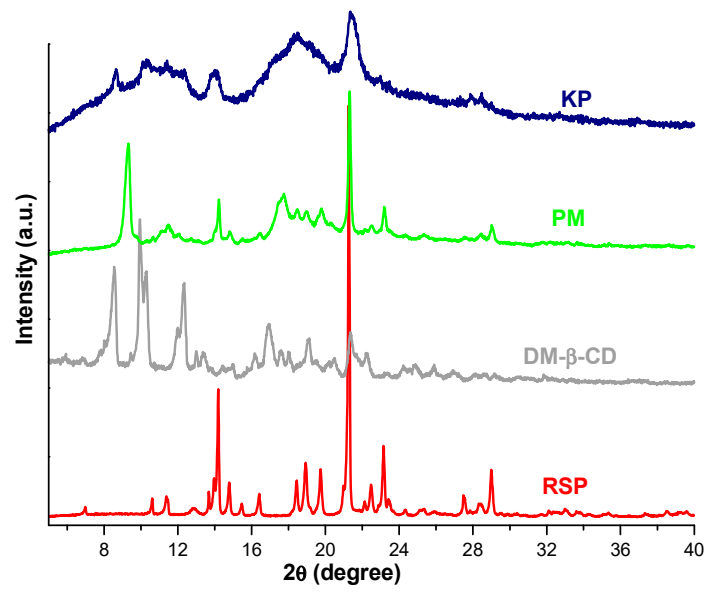

(a)

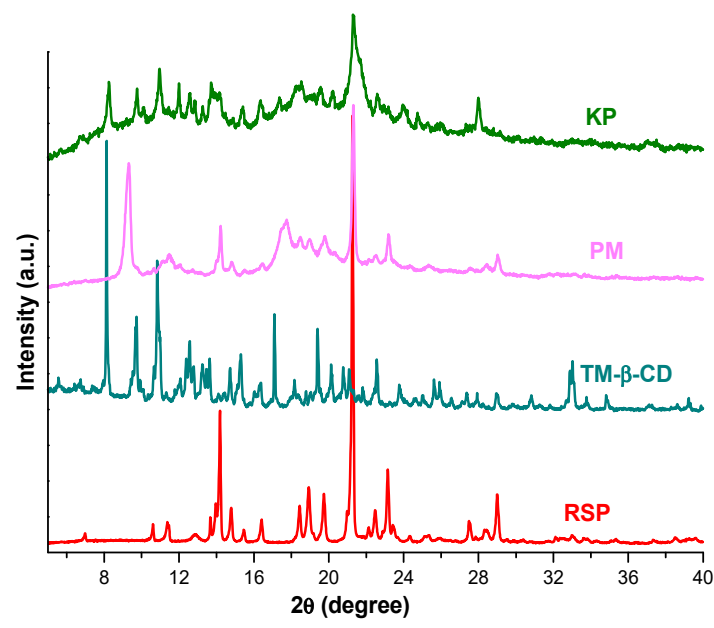

(b)

Figure 5. XRD spectra of RSP, DM- $\beta-C D$ and their PM and KP (a); RSP, TM- $\beta-C D, R S P / T M-\beta-C D$ PM and KP (b).

The diffractometric profile of RSP reveals two peaks of high intensity at 14.19 and $21.272 \theta$ and other characteristic peaks at $14.79 ; 18.44 ; 18.93 ; 19.74 ; 23.15$ and $29.002 \theta$, indicating the crystalline nature of the drug substance. The diffraction pattern of DM- $\beta-C D$ also shows a typical crystalline structure with sharp peaks at $8.54 ; 9.95 ; 10.29 ; 12.31 ; 16.89 ; 19.04$ and $21.322 \theta$ [11]. In the diffractogram of RSP/DM- $\beta$-CD PM the disappearance of CD peaks from 8.54; 9.95; 10.29 and $12.312 \theta$ and the presence of a new peak at $9.382 \theta$ can be noticed. Furthermore, the lower intensity of characteristic diffraction peaks of both guest and host substances can be observed. Figure 5a shows a different diffractometric profile of RSP/DM- $\beta$-CD KP from those of parent compounds, with main peaks at 8.65; 14.05 and $21.352 \theta$. In addition, most of the characteristic diffraction peaks of RSP and CD disappeared highlighting an amorphization process of the drug substance in the $\mathrm{KP}$, which is expected to improve RSP solubility and also demonstrates the existence of an interaction between RSP and DM- $\beta$-CD [33].

The derivative TM- $\beta$-CD shows a crystalline nature (Figure $5 \mathrm{~b}$ ) confirmed by the presence of sharp peaks at $8.14 ; 9.73 ; 10.84 ; 12.58 ; 15.31 ; 17.09 ; 19.40 ; 22.572 \theta$ [10] in its PXRD spectrum. The RSP/TM- $\beta$-CD PM diffraction pattern exhibits the disappearance of CD peaks at $8.14 ; 9.73$ and $10.842 \theta$ along with a diminution of the characteristic crystalline reflections of RSP and CD, indicating that the new compound is less crystalline than the drug and TM- $\beta-C D$ alone. An important reduction in crystallinity is noticed in the diffractometric profile of RSP/TM- $\beta$-CD KP together with the appearance of new characteristic reflections (i.e., at 11.99; $12.88 ; 13.71$ and $27.982 \theta$ ) which provides evidence that a new compound is obtained as a result of inclusion complex formation between drug substance and TM- $\beta-C D$ [34].

\subsection{Thermal Metods}

The thermoanalytical curves (TG/DTG/HF) for RSP, DM- $\beta-C D, T M-\beta-C D$, physical mixtures of drug substance and CDs and RSP/CD KP, respectively, are shown in Figure 6a-g. 


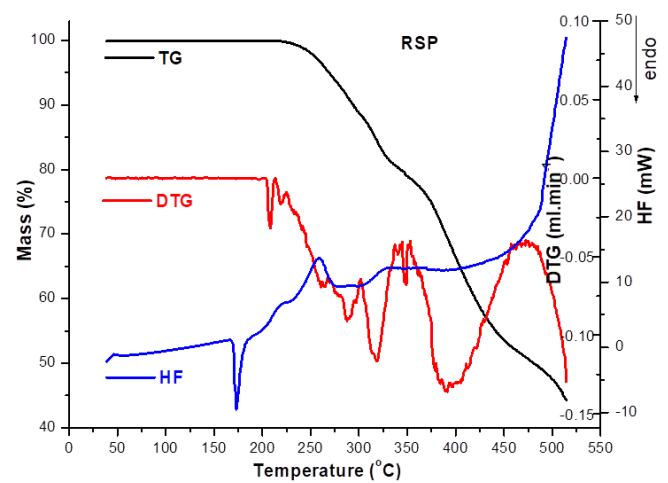

(a)

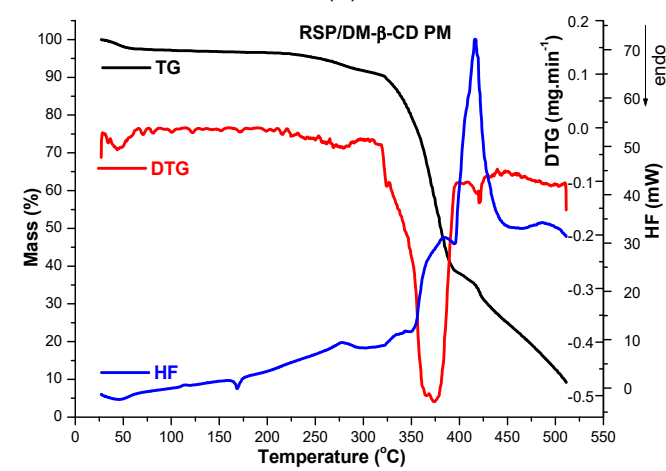

(c)

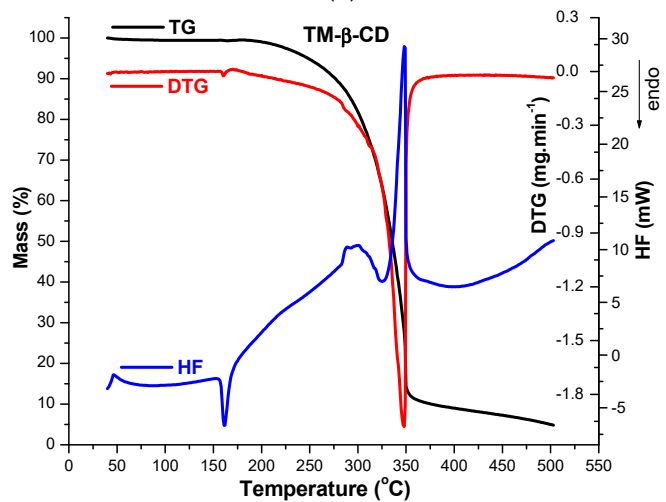

(e)

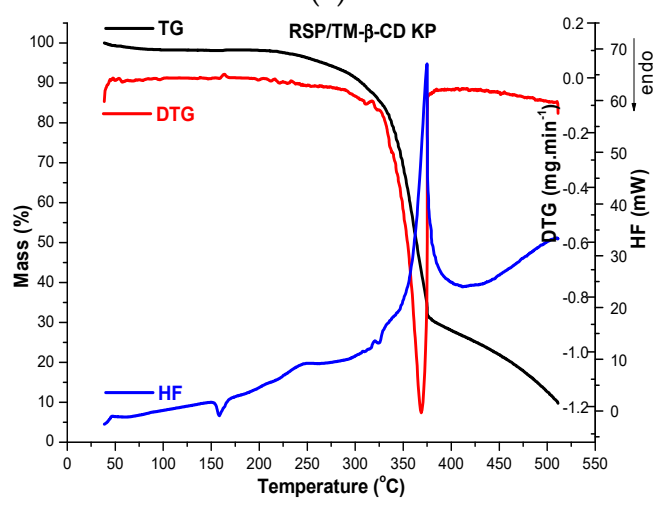

(g)

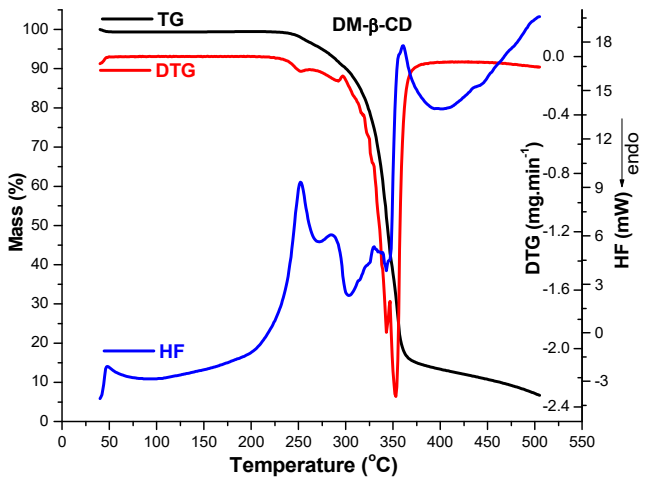

(b)

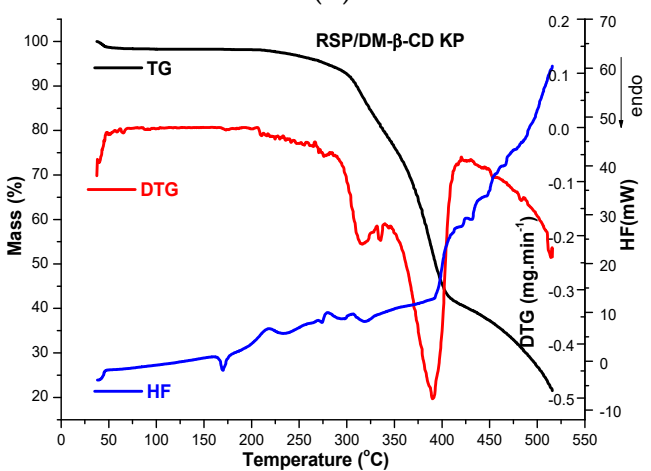

(d)

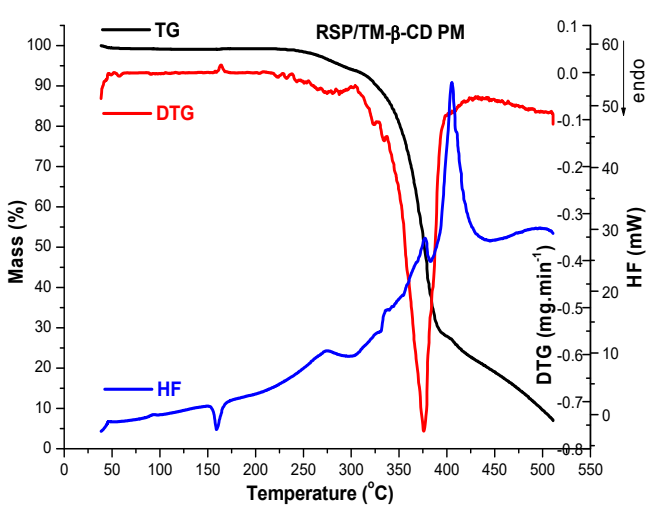

(f)

Figure 6. Thermoanalytical curves (thermogravimetry (TG)/derivative thermogravimetry (DTG)/heat flow (HF)) of: RSP (a); DM- $\beta$-CD (b); RSP/DM- $\beta$-CD physical mixture (PM) (c); RSP/DM- $\beta$-CD kneaded products (KP) (d); TM- $\beta-\mathrm{CD}(\mathbf{e})$; RSP/TM- $\beta-\mathrm{CD}$ PM (f) and RSP/TM- $\beta-\mathrm{CD} \mathrm{KP}(\mathrm{g})$ in air atmosphere, $40-500{ }^{\circ} \mathrm{C}$ temperature range and heating rate of $10{ }^{\circ} \mathrm{C} \cdot \mathrm{min}^{-1}$. 
The TG curve of RSP indicates that the drug substance has a considerable high thermal stability, since no mass loss occurs up to $206{ }^{\circ} \mathrm{C}$. At temperatures higher than $206{ }^{\circ} \mathrm{C}$, a continuous mass loss process is highlighted up to $515^{\circ} \mathrm{C}(\Delta m=55.6 \%)$, as RSP suffers molecular breakdowns due to thermal-induced thermooxidations. The decomposition pathway of RSP is complex, this fact being sustained by the DTG curve, where three distinct regions can noticed, as follows: the first one between 200 and $226{ }^{\circ} \mathrm{C}$ (peak at $209^{\circ} \mathrm{C} ; \Delta m=0.3 \%$ ), the second, in the temperature range of $226-350{ }^{\circ} \mathrm{C},(\mathrm{main}$ peak at $319{ }^{\circ} \mathrm{C} ; \Delta m=20.73 \%$ ) and the last one between 350 and $474{ }^{\circ} \mathrm{C}$ (peak at $391{ }^{\circ} \mathrm{C}, \Delta m=28.2 \%$ ). At temperatures higher than $474^{\circ} \mathrm{C}$, the degradation occurs rapidly, up to $515^{\circ} \mathrm{C}$. The HF curve of RSP reveals an endothermic peak at $173^{\circ} \mathrm{C}$ corresponding to the RSP melting $[25,35]$ and a small gradual exotherm event with $T_{\text {peak }}=259^{\circ} \mathrm{C}$ assigned to the first process of drug thermal degradation (Figure 6a). A considerable exothermal effect appears above $474{ }^{\circ} \mathrm{C}$, accompanying the rapid mass loss on the TG curve.

The thermal profile of DM- $\beta-C D$ (Figure $6 b$ ) is relatively simplistic and reveals a good thermal stability of this cyclodextrin up to $232{ }^{\circ} \mathrm{C}$, when the decomposition process begins, showing DTG peaks at 343 and $353^{\circ} \mathrm{C}$, respectively. The HF curve of DM- $\beta$-CD shows exothermic effects at 252,286 and $360^{\circ} \mathrm{C}$ attributed to the thermooxidation processes of $\mathrm{CD}$, its melting being probably accompanied and overlapped with these thermooxidations [11,36]. At $500{ }^{\circ} \mathrm{C}$, the solid char has a residual mass $6.73 \%$, so that the degradation of this functionalized polysaccharide is almost complete at this temperature.

Significant changes are observed in the thermal curves of RSP/DM- $\beta$-CD binary products when compared with those of the parent compounds. Thus, the RSP endothermic melting peak exhibits a reduction in its intensity and is shifted to lower temperature in HF curves of both PM $\left(T_{\text {peak }}=169^{\circ} \mathrm{C}\right)$ and $\mathrm{KP}\left(T_{\text {peak }}=170^{\circ} \mathrm{C}\right)$. The RSP exothermic event is displaced to lower temperature in the HF curve of $\mathrm{KP}\left(T_{\text {peak }}=219^{\circ} \mathrm{C}\right)$, while in the PM curve an exothermic peak appears at higher temperature, i.e., $278^{\circ} \mathrm{C}$. Furthermore, the exothermic event in the cyclodextrin HF curve from $360^{\circ} \mathrm{C}$ appears in the thermal curve of RSP/DM- $\beta$-CD PM at $416{ }^{\circ} \mathrm{C}$ (Figure $6 \mathrm{c}$ ), showing significant reduction in the peak and it is not any more present in HF curve of RSP/DM- $\beta-C D$ KP (Figure $6 \mathrm{~d}$ ).

The HF curve of TM- $\beta$-CD shows an endothermic event with a maximum at $161^{\circ} \mathrm{C}$ assigned to the melting of the substance (Figure 6e). CD presents a good thermal stability up to $190{ }^{\circ} \mathrm{C}$, when the main decomposition process starts, as the TG/DTG curves show (DTG ${ }_{\max }=348{ }^{\circ} \mathrm{C}$ ); an exothermic event with a maximum at $348^{\circ} \mathrm{C}$ seen in the HF curve of CD accompanies this process [10].

Notable differences are also observed in the thermal profile of binary systems RSP/TM- $\beta$-CD PM and KP (Figure 6f,g). HF curves of PM and KP binary compounds reveal endothermic peaks at $159^{\circ} \mathrm{C}$ and $158^{\circ} \mathrm{C}$, respectively, which correspond to the CD melting; they show significant reduction and are slightly shifted to lower temperature in comparison with the pure substance $\left(161^{\circ} \mathrm{C}\right)$. The endothermic peak associated with RSP melting is no longer visible in the curves of both PM and KP; the TM- $\beta-C D$ exothermic peak is displaced to higher temperature in the curve of PM $\left(\left(T_{\text {peak }}=405^{\circ} \mathrm{C}\right)\right.$ and $\mathrm{KP}\left(T_{\text {peak }}=374^{\circ} \mathrm{C}\right)$.

Thermoanalytical methods are among of the most used techniques to characterize the encapsulation of drug substances in the CD cavity and to prove the inclusion complex formation. The thermal profiles of guest molecules that are entrapped in the CD cavity are generally changed $[33,34,37,38]$. The disappearance of the melting process of RSP from the HF curve of RSP/TM- $\beta-C D$ KP and its displacement to a lower temperature in the curve of RSP/DM- $\beta-C D$ KP together with the displacement of the RSP exothermic event to different temperatures in both RSP/DM- $\beta-C D$ KP and RSP/TM- $\beta-C D$ $\mathrm{KP}$ suggest an interaction between drug substance and the two cyclodextrins, as a result of formation of guest-host inclusion complexes.

\subsection{FTIR Spectroscopy}

FTIR spectra of RSP, DM- $\beta-C D, T M-\beta-C D, R S P / C D$ binary products (PM and KP) are shown in Figure 7. 


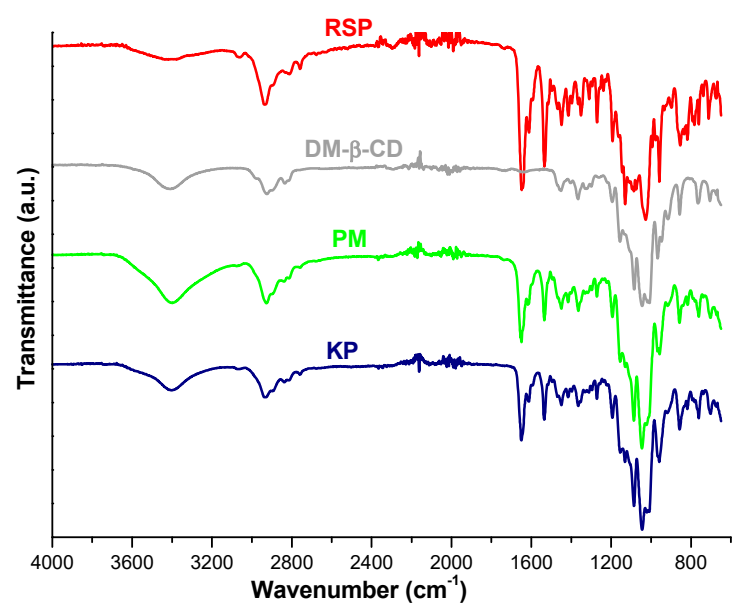

(a)

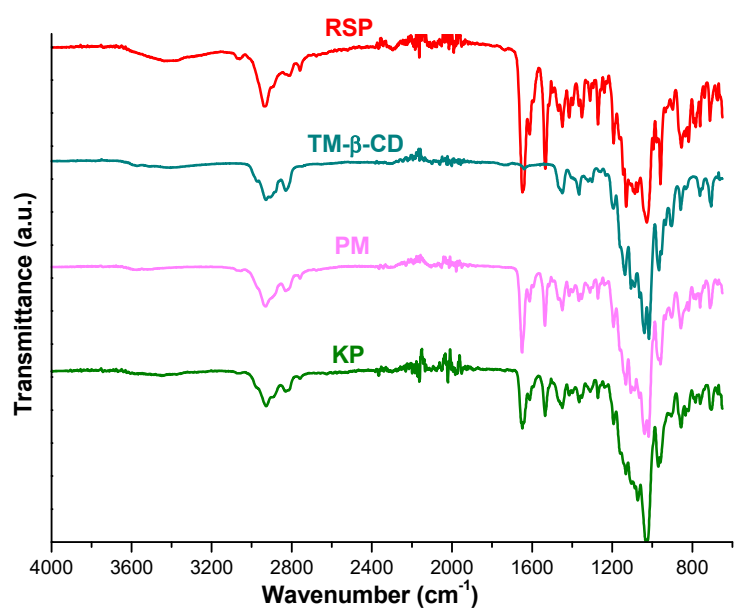

(b)

Figure 7. FTIR spectra of RSP, DM- $\beta-C D$ and their corresponding products PM and KP (a); RSP, TM- $\beta-C D$ and their PM and KP (b).

The spectral pattern of RSP exhibits characteristic prominent bands at $1648 \mathrm{~cm}^{-1}$ assigned to $\mathrm{C}=\mathrm{O}$ stretching vibration from tetrahydropyrido-pyrimidinone ring, at $1534 \mathrm{~cm}^{-1}$ due to $C=C$ stretching vibration of the aromatic ring, at $1027 \mathrm{~cm}^{-1}$ corresponding to $\mathrm{C}_{\mathrm{ar}}-\mathrm{O}$ stretching from the benzoxazole ring. Other RSP characteristic bands can be noticed at 2936, 2812, $2759 \mathrm{~cm}^{-1}$ (aliphatic C-H stretching), at $1414 \mathrm{~cm}^{-1}$ (aliphatic $\mathrm{C}-\mathrm{H}$ bending), at $3063 \mathrm{~cm}^{-1}$ (aromatic $\mathrm{C}-\mathrm{H}$ stretching), at 959, 854, $816 \mathrm{~cm}^{-1}$ (aromatic $\mathrm{C}-\mathrm{H}$ bending). $\mathrm{C}-\mathrm{N}$ stretching vibration appears at $1352 \mathrm{~cm}^{-1}, \mathrm{C}=\mathrm{N}$ stretching arises at $1449 \mathrm{~cm}^{-1}$ and $\mathrm{C}_{\mathrm{ar}}-\mathrm{F}$ stretching vibration is observed at $1130 \mathrm{~cm}^{-1}[22,24]$.

The FTIR spectrum of DM- $\beta-C D$ reveals a broad absorption band in the spectral region of $3500-3300 \mathrm{~cm}^{-1}$ assigned to $\mathrm{O}-\mathrm{H}$ stretching vibration of non-methylated hydroxyl moieties and a large region below $1500 \mathrm{~cm}^{-1}$ which displays distinct peaks, characteristic to the cyclodextrin ring [11,36,39].

The FTIR spectra of both RSP/DM- $\beta$-CD KP and PM show differences in relation with those of the pure compounds. Thus, the RSP bands that correspond to $\mathrm{C}=\mathrm{C}$ stretching from aromatic ring and $\mathrm{C}=\mathrm{O}$ stretching vibration shifted from 1534 and $1648 \mathrm{~cm}^{-1}$ in pure RSP to 1535 and $1649 \mathrm{~cm}^{-1}$ in both $\mathrm{PM}$ and KP. In addition, the spectral band associated with aromatic C-H banding from $959 \mathrm{~cm}^{-1}$ in pure drug is displaced to $957 \mathrm{~cm}^{-1}$ in PM. Furthermore, the characteristic bands of RSP assigned to $\mathrm{C}_{\mathrm{ar}}-\mathrm{F}$ stretching, to $\mathrm{C}_{\mathrm{ar}}-\mathrm{O}$ stretching and to aromatic $\mathrm{C}-\mathrm{H}$ bending from $816 \mathrm{~cm}^{-1}$ disappeared in binary products $\mathrm{KP}$ and $\mathrm{PM}$, giving evidence about the interaction between drug substance and $\mathrm{CD}$ (Figure 7a).

The UATR-FTIR spectrum of TM- $\beta-C D$ shows the characteristic peaks of CD at $2929 \mathrm{~cm}^{-1}$ corresponding to symmetric and asymmetric $\mathrm{C}-\mathrm{H}$ stretching vibration from $\mathrm{CH}_{2}$, at $1365 \mathrm{~cm}^{-1}$ assigned to $\mathrm{C}-\mathrm{H}$ bending from $\mathrm{CH}_{2}$, at $1016 \mathrm{~cm}^{-1}$ due to $\mathrm{C}-\mathrm{C}-\mathrm{O}$ stretching vibration. Moreover, characteristic bands are identified in the spectral region $1076-1022 \mathrm{~cm}^{-1}$ attributed to $\mathrm{C}-\mathrm{O}-\mathrm{C}$ stretching vibrations $[10,40]$. The broad band placed in $3500-3300 \mathrm{~cm}^{-1}$ region $(\mathrm{O}-\mathrm{H}$ stretching vibration), characteristic for DM- $\beta-C D$ was not observed in the TM- $\beta-C D$ spectrum due to the methylation of the $\mathrm{OH}$ moieties.

Differences are also noticed in the IR spectra of RSP/TM- $\beta$-CD KP and PM when compared with spectra of the parent compounds. The RSP characteristic bands associated to $\mathrm{C}=\mathrm{C}$ stretching vibration of the aromatic ring and $\mathrm{C}=\mathrm{O}$ stretching vibration located at 1534 and $1648 \mathrm{~cm}^{-1}$ in pure RSP spectrum shifted to higher wavenumbers, $1536 \mathrm{~cm}^{-1}$ in PM, $1535 \mathrm{~cm}^{-1}$ in $\mathrm{KP}, 1650 \mathrm{~cm}^{-1}$ in PM and $1649 \mathrm{~cm}^{-1}$ in KP, respectively. Moreover, the RSP band assigned to $C_{a r}-O$ stretching vibration from $1027 \mathrm{~cm}^{-1}$ in pure drug is shifted to $1030 \mathrm{~cm}^{-1}$ in the PM spectrum and to $1032 \mathrm{~cm}^{-1}$ in the KP. The RSP bands that correspond to aromatic $\mathrm{C}-\mathrm{H}$ bending from $959,854,816 \mathrm{~cm}^{-1}$ shifted to $957,856,825 \mathrm{~cm}^{-1}$ in the KP spectrum, and the band associated to aliphatic $\mathrm{C}-\mathrm{H}$ stretching from $2812 \mathrm{~cm}^{-1}$ is displaced 
to $2816 \mathrm{~cm}^{-1}$. Additionally, the band of $\mathrm{C}_{\mathrm{ar}}-\mathrm{F}$ stretching vibration from $1130 \mathrm{~cm}^{-1}$ in the spectral pattern of pure drug sifted to $1128 \mathrm{~cm}^{-1}$ in PM spectrum and it is no more present in the KP spectrum. By analyzing the spectral data, we also found a new band at $1073 \mathrm{~cm}^{-1}$ in the KP spectrum without a correspondent in the spectral profile of the parent substances (Figure $7 \mathrm{~b}$ ).

The results of UATR-FTIR studies reveal both the reduction in intensity of RSP bands along with their displacement to different wavenumbers and the disappearance of several characteristic peaks in the KP and PM spectra. These results clearly prove the existence of an interaction between RSP and the two methylated CD and also support the results of molecular docking studies.

\subsection{Solubility Profile of RSP/CD Kneaded Products}

RSP solubility in the inclusion complexes obtained using the kneading method was assessed by means of the shake-flask method $[10,11,41]$. The RSP concentration in the saturated solution was evaluated using UV spectrophotometric measurements. Since both DM- $\beta-C D$ and TM- $\beta-C D$ solutions in phosphate buffer $0.1 \mathrm{M}$ ( $\mathrm{pH}$ 7.4) do not present UV absorption in the spectral range of 210-310 nm (Figure 8a), a calibration curve of RSP obtained using absorbance values from $236 \mathrm{~nm}$, at $25^{\circ} \mathrm{C}$ (Figure $8 \mathrm{~b}, \mathrm{c}$ ) was used to estimate the drug substance in the inclusion complexes.

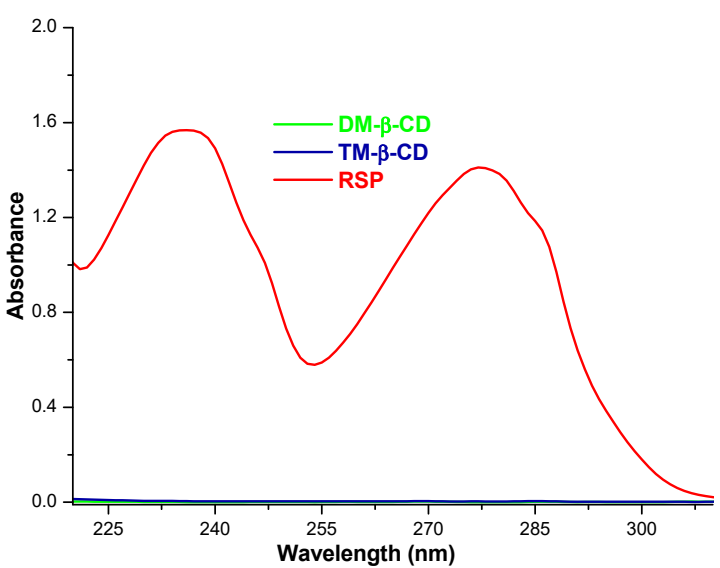

(a)

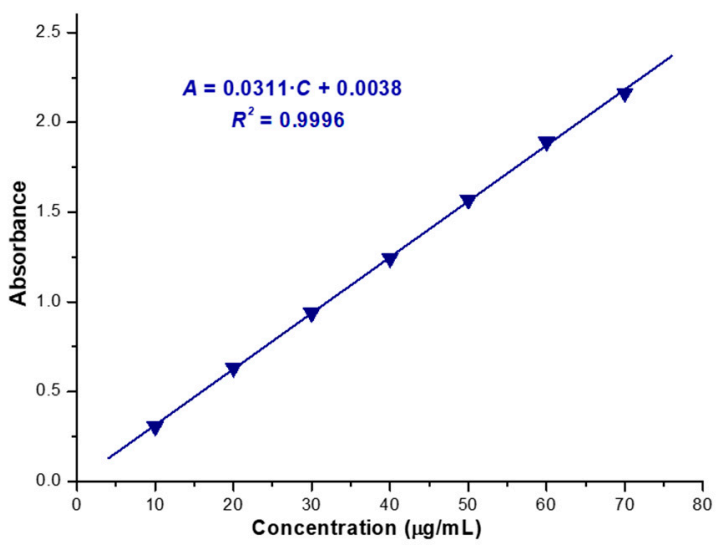

(c)

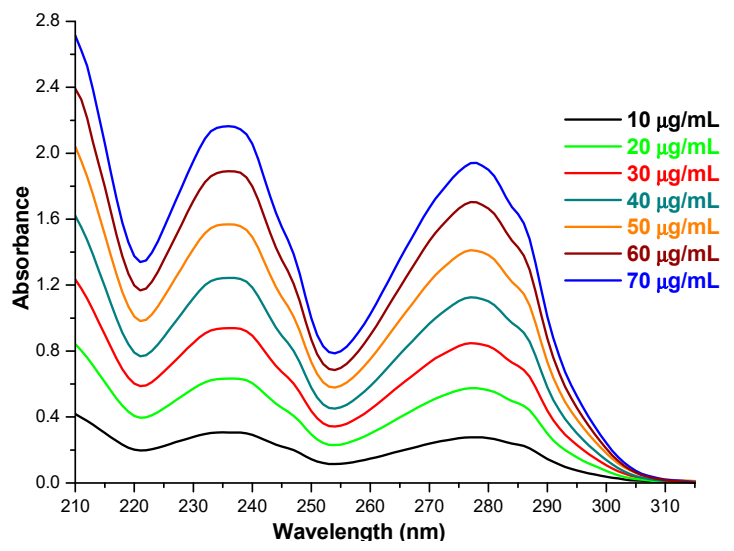

(b)

Figure 8. Absorption spectra of: $D M-\beta-C D 130 \mu \mathrm{g} / \mathrm{mL}, \mathrm{TM}-\beta-\mathrm{CD} 142 \mu \mathrm{g} / \mathrm{mL}, \mathrm{RSP} 30 \mu \mathrm{g} / \mathrm{mL}$ in phosphate buffer $0.1 \mathrm{M}$ (pH 7.4), at $25^{\circ} \mathrm{C}$ (a); RSP $10-70 \mu \mathrm{g} / \mathrm{mL}$ in phosphate buffer $0.1 \mathrm{M}(\mathrm{pH} 7.4)$, at $25^{\circ} \mathrm{C}(\mathbf{b})$; RSP calibration curve (c).

The solubility of RSP in the KP with DM- $\beta-C D$ and TM- $\beta-C D$, calculated as an average of five experimental determinations is $1252.063 \pm 0.021 \mu \mathrm{g} / \mathrm{mL}$ and $629.627 \pm 0.014 \mu \mathrm{g} / \mathrm{mL}$, respectively. Clear solutions were obtained in standard controlled experiments, when $16.41 \mathrm{mg}$ of RSP/DM- $\beta-\mathrm{CD}$ 
$\mathrm{KP}$ and $8.64 \mathrm{mg}$ of RSP/TM- $\beta$-CD KP were dissolved in $5 \mathrm{~mL} 0.1 \mathrm{M}$ phosphate buffer ( $\mathrm{pH}$ 7.4) at room temperature.

The saturation solubility studies reveal an increase in RSP solubility in phosphate buffer $0.1 \mathrm{M}$, $\mathrm{pH} 7.4$ of 1.16 -fold in the presence of TM- $\beta-\mathrm{CD}$ and of 2.32 -fold in the presence of DM- $\beta-C D$ as compared with free RSP $(540.007 \pm 0.003 \mu \mathrm{g} / \mathrm{mL})$. These results demonstrate the solubilizing effect of the two $\mathrm{CD}$ derivatives.

\section{Materials and Methods}

\subsection{Materials}

Risperidone (as Pharmaceutical Secondary Standard) was purchased from Sigma-Aldrich. The two cyclodextrin derivatives, heptakis(2,6-di-O-methyl)- $\beta$-cyclodextrin and heptakis(2,3,6-tri-O-methyl)- $\beta$ cyclodextrin were acquired from Cyclolab R\&L Ltd. (Budapest, Hungary). All other reagents and chemicals used were of analytical purity.

\subsection{Stoichiometry Determination of RSP/CD Inclusion Complexes}

All UV spectra were recorded using a SPECTRONIC UNICAM-UV 300 UV-VISIBLE double beam spectrophotometer with $1 \mathrm{~cm}$ matched quartz cells.

Job's method was employed to evaluate the stoichiometry of the inclusion complexes between RSP and CDs [10,29]. Job's plot was generated based on UV spectroscopic measurements. To this end, equimolar $4.87 \times 10^{-5} \mathrm{M}$ solutions of RSP and each CD (DM- $\beta-C D$ and TM- $\beta-C D$, respectively) were prepared in $0.1 \mathrm{M}$ phosphate buffer of $\mathrm{pH} 7.4$ and then mixed to a standard volume, varying the RSP molar ratio from 0.0 to 1.0. A dilution set of the RSP stock solution was also prepared similarly, in the same solvent. The solutions were stirred, and the absorbance of all solutions was recorded at $236 \mathrm{~nm}$. The plot of $\triangle A\left(\triangle A=A-A_{0}\right)$, the difference in RSP absorbance in the presence $(A)$ and in the absence $\left(A_{0}\right)$ of CDs vs. RSP mole fraction $R$ was generated.

\subsection{Molecular Modeling Studies}

In order to visualize the interaction between RSP, DM- $\beta-C D$ and TM- $\beta-C D$, the molecular docking technique was used. The DM- $\beta-C D$ structure used in this work was generated from the curated coordinates of ligand 2QKH (X-ray diffraction, resolution $1.9 \mathrm{~A}$ ) downloaded from the Protein Data Bank database [42]. The methyl groups were manually added on free hydroxyl groups from the 2 and 6 positions (GaussView 5, Semichem Inc., Shawnee Mission, KS, USA) from $\beta$-CD. For TM- $\beta$-CD the same initial $\beta-C D$ was used, methyl groups being manually added on all free hydroxyl groups in order to obtain a fully permethylated structure (GaussView 5, Semichem Inc). CDs were optimized in the same manner with RSP (DFT/B3LYP/6-311G). All dihedral angles of the methoxy groups were homogenized, the resulting conformations being compatible with an unhindered CD cavity. Three-dimensional coordinates of RSP were generated using the Gaussian program suite at DFT/B3LYP/6-311G optimization.

As the expected stoichiometry of RSP/CD inclusion complexes was 2:1, two consecutive docking cycles were carried out starting and selecting the best result from each cycle.

The molecular docking analysis was performed using the Autodock 4.2.6 software together with the AutoDockTools [30]. The docking between RSP and CD involves adding all the polar hydrogens, computing the Gasteiger charge; the grid box was created using Autogrid 4 with $50 \times 50 \times 50 \AA$ in $x, y$ and $\mathrm{z}$ directions with $0.375 \AA$ spacing from the $\mathrm{CD}$ center. All the calculations were performed in a vacuum. The Lamarckian genetic algorithm with a population size of 150 and a number of 50 runs was applied in the docking process. All the other parameters were used with the default values. Molecular modeling figures were generated using PyMol (The PyMOL Molecular Graphics System, Version 2.0 Schrödinger, LLC, New York, NY, USA) [32]. To validate the docking method's repeatability and 
reproducibility we realized redocking and then expressed the results as RMSD in $\AA$ using Discovery Studio software. We performed all the calculations in triplicate and expressed them as an average.

\subsection{Preparation of the Solid Inclusion Complexes and Physical Mixtures}

The inclusion complexes of RSP with DM- $\beta-C D$ and TM- $\beta-C D$ were prepared using the kneading method in a 2:1 guest:host molar ratio. For RSP/DM- $\beta$-CD KP preparation $0.1908 \mathrm{~g}$ RSP and $0.3093 \mathrm{~g}$ $\mathrm{CD}$ were weighed and their mixture was pulverized in an agate mortar and triturated with $0.5 \mathrm{~g}$ ethanol:HCl $0.1 \mathrm{M}$ solution $(1: 1, \mathrm{~m} / \mathrm{m})$. To obtain the RSP/TM- $\beta$-CD inclusion complex $0.1824 \mathrm{~g}$ RSP and $0.3174 \mathrm{~g}$ TM- $\beta-C D$ were accurately weighed and the resulted mixture was pulverized and triturated with 0.50 g ethanol: $\mathrm{HCl} 0.1 \mathrm{M}$ solution $(1: 1, \mathrm{~m} / \mathrm{m})$ until a homogeneous paste was obtained. The paste was kneaded for $45 \mathrm{~min}$ and during this process an appropriate quantity of solvent was added to maintain the paste consistency. The final product was dried at room temperature and then in the oven, at $40{ }^{\circ} \mathrm{C}$ for $24 \mathrm{~h}$. The obtained kneaded products were pulverized and passed through a $75-\mu \mathrm{m}$ size sieve.

Additionally, physical mixtures of RSP and every cyclodextrin in the same molar ratio as the kneaded products were prepared. Risperidone and the host substances were mixed in the agate mortar and pestle for $10 \mathrm{~min}$, in solvent-free manner.

\subsection{X-ray Diffraction Studies}

The PXRD studies were performed using a diffractometer produced by Bruker, model D8 Advance powder X-ray. The X-ray diffraction patterns were collected with $\mathrm{CuK} \alpha$ radiation $(40 \mathrm{kV}, 40 \mathrm{~mA})$ and a $\mathrm{Ni}$ filter over the interval of $5-40^{\circ}$ angular domain $(2 \theta)$.

\subsection{Thermal Metods}

The thermal profile of RSP, CDs, physical mixtures and kneaded products was evaluated using a Perkin-Elmer DIAMOND TG/DTA instrument. For this purpose samples of about 3-4 mg were placed in aluminum crucibles and were analyzed under air atmosphere at a flow rate of $100 \mathrm{~mL} \mathrm{~min}^{-1}$, over the temperature range of $40-500{ }^{\circ} \mathrm{C}$, with heating rate of $10^{\circ} \mathrm{C} \mathrm{min}^{-1}$.

\subsection{FTIR Spectroscopy}

The FTIR spectra of RSP, DM- $\beta-C D$, TM- $\beta-C D, R S P / C D$ kneaded products and physical mixtures were recorded using a Perkin Elmer SPECTRUM 100 device. The data were collected directly on solid samples using a UATR device in the spectral domain $4000-600 \mathrm{~cm}^{-1}$. Spectra were designed after 16 co-added scans, with a spectral resolution of $4 \mathrm{~cm}^{-1}$.

\subsection{Solubility Profile of RSP/CD Kneaded Products}

The saturation shake-flask method was applied to evaluate the change in RSP solubility upon complexation with CDs. An excess amount of RSP, RSP/DM- $\beta$-CD and RSP/TM- $\beta$-CD kneaded products was added in $5 \mathrm{~mL}$ of phosphate buffer $0.1 \mathrm{M}(\mathrm{pH}$ 7.4) so that saturated solutions were obtained. After shaking for $24 \mathrm{~h}$ at the ambient temperature, the samples were filtered using $0.45 \mu \mathrm{m}$ cellulose acetate filter. After appropriate dilution, the absorption intensity of the filtrate was recorded at $236 \mathrm{~nm}$. The RSP quantification was carried out by means of calibration curve. To obtain the standard curve a set of RSP solutions in phosphate buffer $0.1 \mathrm{M}$ of pH 7.4 with concentrations between 10 and $70 \mu \mathrm{g} / \mathrm{mL}$ were prepared. The absorbance of the calibration standards was recorded at $236 \mathrm{~nm}$ and the data were used to draw the standard curve plotting the absorbance $(A)$ against the concentration $(C$, $\mu \mathrm{g} / \mathrm{mL}$ ). The RSP calibration curve is described by the equation: $A=0.0311 \cdot C-0.0038$, with $R=0.9998$. 


\section{Conclusions}

In this study the molecular encapsulation of antipsychotic drug RSP by two methylated $\beta$-cyclodextrin, namely DM- $\beta-C D$ and TM- $\beta-C D$ was investigated in solution and in solid state by means of UV-spectroscopy, thermogravimetry, derivative thermogravimetry, heat flow, powder X-ray diffractometry, FTIR spectroscopy and also, by docking studies. The experimental results reveal different physicochemical properties of the binary products obtained by the kneading method as compared to the parent substances, thus suggesting the existence of a real interaction between RSP and CD derivatives as a result of the inclusion complex formation in the stoichiometry of 2:1 as the Job method indicates. The solubility studies highlight a higher increase in RSP solubility when the DM- $\beta-C D$ is used. The results of this study reveal that the RSP/DM- $\beta-C D$ inclusion complex can represent a starting point for further research in developing new formulations containing RSP, with enhanced bioavailability and stability.

Author Contributions: Conceptualization, L.S., I.-M.T., A.L. and I.L.; formal analysis, D.C. and R.-M.V.; investigation, L.S., I.-M.T., A.L., G.V., P.B., M.M. and R.-M.V.; methodology, L.S., C.T. and I.L.; project administration, L.S.; resources, I.-M.T., D.C., G.V. and P.B.; software, R.-M.V.; supervision, A.L. and I.L.; validation, I.-M.T., A.L. and I.L.; visualization, C.T.; writing—original draft, L.S., I.-M.T. and R.-M.V.; writing—review and editing, L.S., A.L. and I.L. All authors have read and agreed to the published version of the manuscript.

Funding: This research received no external funding.

Conflicts of Interest: The authors declare no conflict of interest.

\section{References}

1. Carneiro, S.B.; Duarte, F.Í.C.; Heimfarth, L.; Quintans, J.D.S.S.; Quintans-Júnior, L.J.; Júnior, V.F.D.V.; De Lima, Á.A.N. Cyclodextrin-drug inclusion complexes: In vivo and in vitro approaches. Int. J. Mol. Sci. 2019, 20, 642. [CrossRef] [PubMed]

2. Crini, G.; Fourmentin, S.; Fenyvesi, É.; Torri, G.; Fourmentin, M.; Morin-Crini, N. Cyclodextrins, from molecules to applications. Environ. Chem. Lett. 2018, 16, 1361-1375. [CrossRef]

3. Han, D.; Han, Z.; Liu, L.; Wang, Y.; Xin, S.; Zhang, H.; Yu, Z. Solubility enhancement of myricetin by inclusion complexation with heptakis-o-(2-hydroxypropyl)- $\beta$-cyclodextrin: A joint experimental and theoretical study. Int. J. Mol. Sci. 2020, 21, 766. [CrossRef] [PubMed]

4. Gu, W.; Liu, Y. Characterization and stability of beta-acids/hydroxypropyl- $\beta$-cyclodextrin inclusion complex. J. Mol. Struct. 2020, 1201, 127159. [CrossRef]

5. Usacheva, T.; Kabirov, D.; Beregova, D.; Gamov, G.; Sharnin, V.; Biondi, M.; Mayol, L.; D’Aria, F.; Giancola, C. Thermodynamics of complex formation between hydroxypropyl- $\beta$-cyclodextrin and quercetin in water-ethanol solvents at $\mathrm{T}=298.15 \mathrm{~K}$. J. Therm. Anal. Calorim. 2019, 138, 417-424. [CrossRef]

6. Li, S.; Yuan, L.; Chen, Y.; Zhou, W.; Wang, X. Studies on the inclusion complexes of daidzein with $\beta$-cyclodextrin and derivatives. Molecules 2017, 22, 2183. [CrossRef]

7. He, J.; Zheng, Z.P.; Zhu, Q.; Guo, F.; Chen, J. Encapsulation mechanism of oxyresveratrol by $\beta$-cyclodextrin and hydroxypropyl- $\beta$-cyclodextrin and computational analysis. Molecules 2017, 22, 1801. [CrossRef]

8. Simsek, T.; Rasulev, B.; Mayer, C.; Simsek, S. Preparation and characterization of inclusion complexes of $\beta$-cyclodextrin and phenolics from wheat bran by combination of experimental and computational techniques. Molecules 2020, 25, 4275. [CrossRef]

9. Du, F.; Pan, T.; Ji, X.; Hu, J.; Ren, T. Study on the preparation of geranyl acetone and $\beta$-cyclodextrin inclusion complex and its application in cigarette flavoring. Sci. Rep. 2020, 10, 12375. [CrossRef]

10. Tănase, I.M.; Sbârcea, L.; Ledeți, A.; Vlase, G.; Barvinschi, P.; Văruț, R.M.; Dragomirescu, A.; Axente, C.; Ledeț, I. Physicochemical characterization and molecular modeling study of host-guest systems of aripiprazole and functionalized cyclodextrins. J. Therm. Anal. Calorim. 2020, 141, 1027-1039. [CrossRef]

11. Tănase, I.M.; Sbârcea, L.; Ledeţi, A.; Barvinschi, P.; Cîrcioban, D.; Vlase, G.; Văruț, R.M.; Ledeţi, I. Compatibility studies with pharmaceutical excipients for aripiprazole-heptakis (2,6-di-O-methyl)- $\beta$-cyclodextrin supramolecular adduct. J. Therm. Anal. Calorim. 2020, 142, 1963-1976. [CrossRef] 
12. Sbârcea, L.; Udrescu, L.; Ledeţi, I.; Szabadai, Z.; Fuliaş, A.; Sbârcea, C. $\beta$-Cyclodextrin inclusion complexes of lisinopril and zofenopril: Physicochemical characterization and compatibility study of lisinopril- $\beta$-cyclodextrin with lactose. J. Therm. Anal. Calorim. 2016, 123, 2377-2390. [CrossRef]

13. Sbârcea, L.; Ledeţi, I.; Drăgan, L.; Kurunczi, L.; Fuliaş, A.; Udrescu, L. Fosinopril sodium-hydroxypropyl$\beta$-cyclodextrin inclusion complex: Thermal decomposition kinetics and compatibility studies. J. Therm. Anal. Calorim. 2015, 120, 981-990. [CrossRef]

14. Saokham, P.; Muankaew, C.; Jansook, P.; Loftsson, T. Solubility of cyclodextrins and drug/cyclodextrin complexes. Molecules 2018, 23, 1161. [CrossRef] [PubMed]

15. García, A.; Leonardi, D.; Vasconi, M.D.; Hinrichsen, L.I.; Lamas, M.C. Characterization of albendazolerandomly methylated- $\beta$-cyclodextrin inclusion complex and in vivo evaluation of its antihelmitic activity in a murine model of trichinellosis. PLoS ONE 2014, 9, e113296. [CrossRef]

16. Ferreira, E.B.; da Silva Júnior, W.F.; de Oliveira Pinheiro, J.G.; da Fonseca, A.G.; Moura Lemos, T.M.A.; de Oliveira Rocha, H.A.; de Azevedo, E.P.; Mendonça Junior, F.J.B.; De Lima, Á.A.N. Characterization and antiproliferative activity of a novel 2 -aminothiophene derivative- $\beta$-cyclodextrin binary system. Molecules 2018, 23, 3130. [CrossRef]

17. Szente, L.; Szejtli, J. Highly soluble cyclodextrin derivatives: Chemistry, properties, and trends in development. Adv. Drug Deliv. Rev. 1999, 36, 17-28. [CrossRef]

18. Brewster, M.E.; Loftsson, T. Cyclodextrins as pharmaceutical solubilizers. Adv. Drug Deliv. Rev. 2007, 59, 645-666. [CrossRef]

19. Germann, D.; Kurylo, N.; Han, F. Risperidone. In Profiles of Drug Substances, Excipients and Related Methodology; Academic Press Elsevier: San Diego, CA, USA, 2012; Volume 37, pp. 313-361. ISBN 9780123972200.

20. Yunusa, I.; El Helou, M.L. The Use of Risperidone in Behavioral and Psychological Symptoms of Dementia: A Review of Pharmacology, Clinical Evidence, Regulatory Approvals, and Off-Label Use. Front. Pharmacol. 2020, 11, 596. [CrossRef]

21. Love, R.C.; Nelson, M.W. Pharmacology and clinical experience with risperidone. Expert Opin. Pharmacother. 2000, 1, 1441-1453. [CrossRef]

22. Rahman, Z.; Zidan, A.S.; Khan, M.A. Risperidone solid dispersion for orally disintegrating tablet: Its formulation design and non-destructive methods of evaluation. Int. J. Pharm. 2010, 400, 49-58. [CrossRef]

23. Censi, R.; Di Martino, P. Polymorph impact on the bioavailability and stability of poorly soluble drugs. Molecules 2015, 20, 18759-18776. [CrossRef] [PubMed]

24. Shukla, D.; Chakraborty, S.; Singh, S.; Mishra, B. Preparation and in-vitro characterization of Risperidonecyclodextrin inclusion complexes as a potential injectable product. Daru 2009, 17, 226-235.

25. Jug, M.; Kos, I.; Bećirević-Laćan, M. The pH-dependent complexation between risperidone and hydroxypropyl- $\beta$-cyclodextrin. J. Incl. Phenom. Macrocycl. Chem. 2009, 64, 163-171. [CrossRef]

26. El-Barghouthi, M.I.; Masoud, N.A.; Al-Kafawein, J.K.; Zughul, M.B.; Badwan, A.A. Host-guest interactions of risperidone with natural and modified cyclodextrins: Phase solubility, thermodynamics and molecular modeling studies. J. Incl. Phenom. 2005, 53, 15-22. [CrossRef]

27. Savjani, K.T.; Gajjar, A.K.; Savjani, J.K. Drug Solubility: Importance and Enhancement Techniques. ISRN Pharm. 2012, 2012, 1-10. [CrossRef]

28. Job, P. Formation and stability of inorganic complexes in solution. Ann. Chim. 1928, 9, 113-203.

29. Sbârcea, L.; Ledeţi, A.; Udrescu, L.; Văruţ, R.M.; Barvinschi, P.; Vlase, G.; Ledeţi, I. Betulonic acid-Cyclodextrins inclusion complexes. J. Therm. Anal. Calorim. 2019, 138, 2787-2797. [CrossRef]

30. Morris, G.M.; Ruth, H.; Lindstrom, W.; Sanner, M.F.; Belew, R.K.; Goodsell, D.S.; Olson, A.J. Software news and updates AutoDock4 and AutoDockTools4: Automated docking with selective receptor flexibility. J. Comput. Chem. 2009, 30, 2785-2791. [CrossRef]

31. Huey, R.; Morris, G.M.; Olson, A.J.; Goodsell, D.S. A Semiempirical Free Energy Force Field with Charge-Based Desolvation. J. Comput. Chem. 2007, 28, 1145-1152. [CrossRef]

32. DeLano, W.L. PyMOL; DeLano Scientific: San Carlos, CA, USA, 2002.

33. Sbârcea, L.; Udrescu, L.; Drăgan, L.; Trandafirescu, C.; Szabadai, Z.; Bojiţă, M. Fosinopril-cyclodextrin inclusion complexes: Phase solubility and physicochemical analysis. Pharmazie 2011, 66, 584-589. [CrossRef]

34. Sbarcea, L.; Udrescu, L.; Dragan, L.; Trandafirescu, C.; Sasca, V.; Barvinschi, P.; Bojita, M. Characterization of fosinopril natrium-hydroxypropyl- $\beta$-cyclodextrin inclusion complex. Rev. Chim. 2011, 62, 349-351. 
35. Daniel, J.S.P.; Veronez, I.P.; Rodrigues, L.L.; Trevisan, M.G.; Garcia, J.S. Risperidone-Solid-state characterization and pharmaceutical compatibility using thermal and non-thermal techniques. Thermochim. Acta 2013, 568, 148-155. [CrossRef]

36. Circioban, D.; Ledeti, A.; Vlase, G.; Coricovac, D.; Moaca, A.; Farcas, C.; Vlase, T.; Ledeti, I.; Dehelean, C. Guest-host interactions and complex formation for artemisinin with cyclodextrins: Instrumental analysis and evaluation of biological activity. J. Therm. Anal. Calorim. 2018, 134, 1375-1384. [CrossRef]

37. Doile, M.M.; Fortunato, K.A.; Schmücker, I.C.; Schucko, S.K.; Silva, M.A.S.; Rodrigues, P.O. Physicochemical properties and dissolution studies of dexamethasone acetate- $\beta$-cyclodextrin inclusion complexes produced by different methods. AAPS PharmSciTech 2008, 9, 314-321. [CrossRef]

38. Circioban, D.; Ledeti, I.; Suta, L.M.; Vlase, G.; Ledeti, A.; Vlase, T.; Varut, R.; Sbarcea, L.; Trandafirescu, C.; Dehelean, C. Instrumental analysis and molecular modelling of inclusion complexes containing artesunate. J. Therm. Anal. Calorim. 2020, 142, 1951-1961. [CrossRef]

39. Mennini, N.; Maestrelli, F.; Cirri, M.; Mura, P. Analysis of physicochemical properties of ternary systems of oxaprozin with randomly methylated-ß-cyclodextrin and L-arginine aimed to improve the drug solubility. J. Pharm. Biomed. Anal. 2016, 129, 350-358. [CrossRef]

40. Lavorgna, M.; Iacovino, R.; Russo, C.; Di Donato, C.; Piscitelli, C.; Isidori, M. A new approach for improving the antibacterial and tumor cytotoxic activities of pipemidic acid by including it in trimethyl- $\beta$-cyclodextrin. Int. J. Mol. Sci. 2019, 20, 416. [CrossRef]

41. Baka, E.; Comer, J.E.A.; Takács-Novák, K. Study of equilibrium solubility measurement by saturation shake-flask method using hydrochlorothiazide as model compound. J. Pharm. Biomed. Anal. 2008, 46, 335-341. [CrossRef] [PubMed]

42. Protein Data Bank. Available online: http://www.pdb.org/pdb/home/home.do (accessed on 15 October 2020).

Sample Availability: Samples of the compounds are not available from the authors.

Publisher's Note: MDPI stays neutral with regard to jurisdictional claims in published maps and institutional affiliations.

(C) 2020 by the authors. Licensee MDPI, Basel, Switzerland. This article is an open access article distributed under the terms and conditions of the Creative Commons Attribution (CC BY) license (http://creativecommons.org/licenses/by/4.0/). 